\title{
Antioxidant capacity of Lathyrus sativus seeds
}

\author{
Wojciech Rybińskia , Magdalena Karamaćb, Michał Janiak ${ }^{b}$, \\ Andreas Börner ${ }^{\mathrm{c}}$, Natalia Płatosz ${ }^{\mathrm{b}}$ and Ryszard Amarowicz ${ }^{\mathrm{b}}$
}

\author{
anstutute of Plant Genetic, Polish Academy of Sciences, Strzeszyńska 34, 60-479 Poznań, Poland \\ bInstitute of Animal Reproduction anf Food Research, Polish Ascademy of Sciences, Tuwima 10, 10-748 Olsztyn, Poland \\ ${ }^{c}$ Leibniz Institute of Genetics and Crop Plant Research (IPK), 06466 Gatersleben, Germany \\ *Corresponding author: Ryszard Amarowicz, Institute of Animal Reproduction and Food Research, Polish Academy of Sciences, Tuwima \\ Street 10, 10-748 Olsztyn, Poland. E-mail: r.amarowicz@pan.olsztyn.pl \\ DOI: $10.31665 /$ JFB.2020.11242 \\ Received: July 03, 2020; Revised received \& accepted: September 28, 2020 \\ Citation: Rybiński, W., Karamać, M., Janiak, M., Börner, A., Płatosz, N., and Amarowicz, R. (2020). Antioxidant capacity of Lathyrus \\ sativus seeds. J. Food Bioact. 11: 110-118.
}

\begin{abstract}
Grass pea seeds of 30 varieties from Poland, Slovakia, Czech, Russia, Ukraine, Hungary, Bulgaria, India, Iran, Tunisia, Ethiopia, Canada, and Chile were investigated. Phenolic compounds were extracted from seeds into $80 \%$ (v/v) methanol. The total phenolics compounds content of the extracts was determined using Folin-Ciocalteu's phenol reagent. The antioxidant activity was determined using ABTS and FRAP assays. Total phenolic contents ranged from 2.72 to $10.7 \mathrm{mg} / \mathrm{g}$ extract and from 35.9 to $144.7 \mathrm{mg} / 100 \mathrm{~g}$ seeds. The extracts and seeds were characterized using Trolox equivalent antioxidant capacity values of $0.014-0.060 \mathrm{mmol}$ Trolox/g extract and $0.188-0.866 \mathrm{mmol}$ Trolox/100 g seeds, and FRAP values of $0.188-0.866 \mathrm{mmol} \mathrm{Fe}^{2+} / \mathrm{g}$ extract and $0.541-1.398 \mathrm{Fe}^{2+} / 100 \mathrm{~g}$ seeds. The total phenolics content of grass pea extract was correlated with the results of the ABTS $(r=0.854)$ and FRAP $(r=$ $0.958)$ assays. A similar correlation existed between the results of both assays $(r=0.890)$. Phenolic acids were the dominant phenolic compounds of two cultivars of grass pea. Syringic and sinapic acids had the highest amounts while ferulic, $p$-hydroxybenzoic, protocatechuic, and $p$-coumaric acids were present in much lower quantities. Phenolic acids were present in the form of free compounds, esters, and glycosides.
\end{abstract}

Keywords: Grass pea; Legume; Antioxidant activity; Phenolic compounds; Phenolic acids.

\section{Introduction}

Grass pea (Lathyrus sativus) is cultivated in India, Ethiopia, Australia, and other countries from North Africa, Asia, and Europe (Hanbury et al., 2000). It is drought tolerant and thrives with minimal external input of water (Hillocks and Maruthi 2012). Therefore, grass pea is an ideal legume for resource-poor farmers.

Currently grass peas, like lentil, vetch, and chickpea is being cultivated in Europe (Mikić et al., 2011). The reason for the increase acreage of grass pea is the high nutritional value of its seeds (Ennenking 2011). According to Mullan et al (2009), grass pea is characterized by the content of its starch, protein, lipid, and minerals which are similar to those of faba bean and peas.
Grass pea seeds have a high nutritional value (Ennenking 2011). Palmitic and linoleic acids are the major fatty acids of grass pea (Pastor-Cavada et al., 2009). However, grass pea seeds contain a neurotoxin, $\beta$-N-oxalyl-1- $\alpha, \beta$-diamino-propionic acid ( $\beta$-ODAP). This non-protein amino acid causes neurolathyrism, a neurological disease in both humans and domestic animals (Getahun et al., 2002). Fortunately, plant geneticists have managed to produce varieties with $\beta$-ODAP content of $<0.10 \%$ (Kumar et al., 2011). In turn, food technologists have shown that soaking and cooking reduce the content of $\beta$-ODAP in grass pea seeds (Srivastava and Khokhar, 1996; Getahun et al., 2002).

Grass pea seeds after removal of anti-nutritional compounds can be a material for obtaining protein preparations (Pastor-Cavada et al., 2010). Grass pea proteins possess suitable functional 
properties like water and oil absorption capacity, foaming ability, and foaming stability (Aletor et al., 2011).

Phenolic compounds of plant origin play an important role in human nutrition as natural antioxidants. They act as protectors of lipids, proteins and DNA against reactive oxygen and nitrogen species. The results of many studies confirm the high antioxidant potential of legume seeds. It seems that they can play an important role in cardio- and cancer-protection (Shahidi and Ambigaipalan, 2015; Alshikha, et al., 2015; Bouchenak and Lamri-Senhadji, 2013; Yeo and Shahidi, 2020).

The protective effect of consumption of phenolic-rich grains, legumes, berries, nuts, and oilseeds against several chronic diseases was demonstrated by several researcher groups (Valdez et al., 2019; Shahidi et al., 2019a, 2019b).

The present study was aimed to determine the content of total phenolics in grass pea extracts and seeds as well their antioxidant activity.

\section{Materials and methods}

\subsection{Materials}

Seeds of 30 grass pea varieties from Poland, Slovakia, Czech, Russia, Ukraine, Hungary, Bulgaria, India, Iran, Tunisia, Ethiopia, Canada, and Chile were obtained from field experiments conducted in Cerekwica (Poland). For phenotypic features the data from descriptors for Lathyrus sativus were used (IPGRI 2000). After harvest, ten randomly selected plants from each accession were selected for estimation of yield and structure parameters). One hundred seed weight was calculated from weighing and counting at least 200 seeds. The characteristics of those seeds are reported in Table 1.

\subsection{Chemicals and standards}

Organic solvents, the Folin-Ciocalteu's phenol reagent, (+)-catechin, sodium persulfate, 2,2'-azinobis-(3-ethylbenzothiazoline6-sulfonic acid) (ABTS), 2,4,6-tri(2-pyridyl)- $S$-triazine (TPTZ), ferrous chloride, and 6-hydroxy-2,5,7,8-tetramethyl-chroman2-carboxylic acid (Trolox), were purchased from Sigma (Poznan, Poland).

\subsection{Extraction}

Phenolic compounds were extracted from defatted seed samples with hexanes into $80 \%$ methanol $(\mathrm{v} / \mathrm{v})$. Condition of extractions were as follows: $3 \times 30 \mathrm{~min}, 50^{\circ} \mathrm{C}$, a solid-to-solvent ratio of 1:10 $(\mathrm{w} / \mathrm{v})$ (Amarowicz and Shahidi, 2017). Extraction was carried out at $50{ }^{\circ} \mathrm{C}$ for $30 \mathrm{~min}$ in flasks placed in a shaking water bath (Elpan 357, Wrocław, Poland). Methanol from the combined extract was evaporated using a Büchi R-210 rotary evaporator. The sample was then freeze-dried.

\subsection{Total phenolic compounds}

The content of total phenolics in the extracts was determined using Folin-Ciocalteu's phenol reagent (Naczk and Shahidi, 1989). The results were expressed as $(+)$-catechin equivalents/g extract and as $(+)$-catechin equivalents/100 g seeds.

\subsection{ABTS assay}

The Trolox equivalent antioxidant capacity (TEAC) was determined using a method described by Re et al. (1999). For the colorimetric measurement, $2 \mathrm{~mL}$ of ABTS radical cation solution were mixed with $20 \mu \mathrm{L}$ of grass pea extract $(5 \mathrm{mg} / \mathrm{mL})$ and after 6 min the absorbance was read at $734 \mathrm{~nm}$. A calibration curve was plotted using Trolox solution. The results were expressed as mmol Trolox equivalents (TE)/g extract and mmol Trolox equivalents (TE)/100 g seeds.

\subsection{FRAP assay}

The ferric-reducing antioxidant power (FRAP) assay was performed according to Benzie and Strain (1990). The working FRAP reagent $(2.25 \mathrm{~mL})$ was mixed with $75 \mu \mathrm{L}$ of the sample and $225 \mu \mathrm{L}$ of deionized and the absorbance was measured at $593 \mathrm{~nm}$ against a reagent blank after $30 \mathrm{~min}$ incubation. The FRAP values were expressed as $\mathrm{mmol}$ of $\mathrm{Fe}^{2+} / \mathrm{g}$ extract and as mmol of $\mathrm{Fe}^{2+} / 100 \mathrm{~g}$ seeds.

\subsection{Sample preparation for LC-MS analysis}

\subsubsection{Phenolic acids}

For analysis of free phenolic acids extract was dissolved in aqueous methanol $(50 \%, \mathrm{v} / \mathrm{v})$ with addition of $0.95 \%$ formic acid and mixed for $24 \mathrm{~h}$ at $10^{\circ} \mathrm{C}$ in a ThermoMixer (Benchmark Scientific, Saryeville, NJ, USA) and centrifuged at $13,200 \mathrm{~g}$ for $20 \mathrm{~min}$ at $4{ }^{\circ} \mathrm{C}$. The supernatant was collected and the solvent evaporated under a flow of nitrogen.

The extract so obtained was suspended in water, acidified to $\mathrm{pH} 2$, carefully vortexed and sonicated. Free phenolics were extracted using $2 \mathrm{~mL}$ of diethyl ether with sonication. The mixture was centrifuged and the organic layer collected. Extraction was repeated three times and diethyl ether layers were combined, dried under a flow of nitrogen and stored under $-20^{\circ} \mathrm{C}$. Water residue was kept under a flow of nitrogen for 5 min to remove any traces of diethyl. Water residue was mixed with $1 \mathrm{~mL}$ of $4 \mathrm{M} \mathrm{NaOH}$. The mixture was hydrolysed for $4 \mathrm{~h}$ at room temperature under a nitrogen atmosphere with magnetic stirrer. Subsequently, the $\mathrm{pH}$ of the solution was adjusted to 2 with $6 \mathrm{M} \mathrm{HCl}$. Phenolic acids liberated from esters were extracted using diethyl ether as described above The water layer was subjected to acid hydrolysis using $0.2 \mathrm{~mL}$ of $6 \mathrm{M} \mathrm{HCl}$ and the mixture was incubated at $100^{\circ} \mathrm{C}$ for $60 \mathrm{~min}$. After cooling, the $\mathrm{pH}$ was adjusted to 2 with $6 \mathrm{M} \mathrm{NaOH}$. Extraction of phenolic acids liberated from glycosides into diethyl ether was conducted in the same way as described above.

The fractions of phenolic acids were dissolved in $80 \%$ methanol and centrifuged at 13,200 $\mathrm{g}$ for $20 \mathrm{~min}$ at $4{ }^{\circ} \mathrm{C}$. The HPLC-MS analysis was subsequently performed.

\subsubsection{Flavonoids}

The extract before LC-MS analysis was prepared like as the fraction of phenolic acids.

\subsection{LC-MS analysis}

Phenolic acids and flavonoids were separated using the HPLC system (LC-200, Eksigent, Vanghan, ON, Canada). They were iden- 


\section{Table 1. Characteristic of grass seeds investigated in this study}

\begin{tabular}{|c|c|c|c|c|}
\hline No & Accession code & Country of origin & Seed coat colour & Weight of 100 seeds (g) \\
\hline 1 & Nochowo & Poland & Cream & 11.2 \\
\hline 2 & Nochowo & Poland & Cream & 21.2 \\
\hline 3 & UP Lublin & Poland & Cream & 8.3 \\
\hline 4 & LAT 469 & Slovakia & Cream with dark helium & 24.2 \\
\hline 5 & LAT 470 & Slovakia & Cream with dark helium, slightly mottled & 23.8 \\
\hline 6 & LAT 471 & Slovakia & Cream with dark helium & 21.3 \\
\hline 7 & LAT 472 & Slovakia & Cream with dark helium & 24.6 \\
\hline 8 & LAT 473 & Slovakia & Cream, bright & 26.6 \\
\hline 9 & LAT 474 & Slovakia & Bright cream with dark helium & 28.3 \\
\hline 10 & LAT 476 & Slovakia & Cream & 26.7 \\
\hline 11 & LAT 479 & Slovakia & Bright cream with dark helium & 26.8 \\
\hline 12 & LAT 478 & Czech & Cream & 32.5 \\
\hline 13 & LAT 447 & Russia & Cream & 21.6 \\
\hline 14 & LAT 448 & Russia & Cream & 18.3 \\
\hline 15 & LAT 466 & Russia & Cream & 29.2 \\
\hline 16 & LAT 434 & Ukraine & Cream & 26.7 \\
\hline 17 & LAT 465 & Ukraine & Cream & 29.9 \\
\hline 18 & LAT 4011 & Ukraine & Cream & 24.0 \\
\hline 19 & LAT 455 & Hungary & Cream, slightly wrinkled & 46.4 \\
\hline 20 & LAT 494 & Hungary & Cream & 21.6 \\
\hline 21 & LAT 440 & India & Dark brown, slightly mottled & 18.6 \\
\hline 22 & LAT 492 & India & Brown, slightly mottled & 20.0 \\
\hline 23 & LAT 463 & Bulgaria & Cream, slightly mottled & 21.7 \\
\hline 24 & LAT 4076 & Bulgaria & Bright brown to grey, slightly mottled & 14.9 \\
\hline 25 & LAT 451 & Iran & Dark and bright brown & 7.0 \\
\hline 26 & LAT 454 & Tunisia & Cream & 45.8 \\
\hline 27 & LAT 4008 & Ethiopia & Dark brown, mottled & 32.3 \\
\hline 28 & - & Ethiopia & Dark brown, slightly mottled & 9.9 \\
\hline 29 & Canada C & Canada & Cream & 35.1 \\
\hline 30 & UACH 2 & Chile & Cream & 32.3 \\
\hline
\end{tabular}

tified and quantified using a mass spectrometer (QTRAP 5500, AB Sciex, Vaughan, ON, Canada). The system was equipped with triple quadrupole, ion trap and ion source of electrospray ionization (ESI). Separation was conducted using HALO C18 column $(50 \mathrm{~mm} \times 0.5 \mathrm{~mm} \times 2.7 \mathrm{~m}$, Eksigent, Vaughan, ON, Canada); the temperature of $45{ }^{\circ} \mathrm{C}$ was maintained, flow rate was $15 \mu \mathrm{l} / \mathrm{min}$. Solvent A was water with formic acid $(0.9 \%, \mathrm{v} / \mathrm{v})$ and solvent B was acetonitrile with formic acid $(0.9 \%, \mathrm{v} / \mathrm{v})$. Binary gradient was employed and was set up as follows: $0.5 \% \mathrm{~B}$ for $0.5 \mathrm{~min}, 0.5-90 \%$ $\mathrm{B}$ in $1.5 \mathrm{~min}, 90 \% \mathrm{~B}$ for $0.5 \mathrm{~min}, 90-0.5 \% \mathrm{~B}$ in $0.2 \mathrm{~min}$, and $0.5 \%$ $\mathrm{B}$ for $0.3 \mathrm{~min}$. Identification was conducted using ESI-MS/MS detector under the following conditions: negative ionization, curtain gas: $20 \mathrm{~L} / \mathrm{min}$, collision gas: ion spray voltage: $5,300 \mathrm{~V}$, temperature: $350{ }^{\circ} \mathrm{C}, 1$ ion source gas: $35 \mathrm{~L} / \mathrm{min}, 2$ ion source gas: $30 \mathrm{~L} /$ min, declustering potential: $100 \mathrm{~V}$, entrance potential: $10 \mathrm{~V}$, colli- sion energy: $40 \mathrm{eV}$, and collision cell exit potential: $20 \mathrm{~V}$. Identification and quantitation of the phenolic acids and flavonoids were based on the comparison of their retention times and the presence of the respective parent and daughter ion pairs (Multiple Reaction Monitoring method, MRM), with data obtained after analysis of the authentic standards. The external standards $(0.01-0.5 \mathrm{~g} / \mathrm{mL})$ had linear calibration curves with a coefficient of determination of $0.997-0.999$. The results were expressed in $\mathrm{mg} / \mathrm{g}$ of extract and $\mathrm{mg} / 100 \mathrm{~g}$ seeds. All analyses were conducted in triplicate.

\subsection{Statistical analysis}

The results are reported as the mean values of three estimates \pm SD. The relationship between total phenolics content, TEAC, and 
Table 2. Characteristics of the grass pea seeds and their extracts: content of total phenolics and antioxidant activity

\begin{tabular}{|c|c|c|c|c|c|c|}
\hline \multirow[b]{2}{*}{ No } & \multicolumn{2}{|c|}{ Total phenolics } & \multicolumn{2}{|c|}{ TEAC } & \multicolumn{2}{|c|}{ FRAP } \\
\hline & (mg/g extract) & $\begin{array}{l}\text { (mmol Trolox/100 } \\
\text { g seeds) }\end{array}$ & $\begin{array}{l}\text { (mmol Trolox/g } \\
\text { extract) }\end{array}$ & $\begin{array}{l}\text { (mmol Trolox/100 } \\
\text { g seeds) }\end{array}$ & $\begin{array}{l}\text { (mmol Fe } 2+/ g \\
\text { extract) }\end{array}$ & $\begin{array}{l}\text { (mmol Fe2+/100 } \\
\text { g seeds) }\end{array}$ \\
\hline 1 & $4.32 \pm 0.09$ & $77.3 \pm 1.7$ & $0.028 \pm 0.001$ & $0.498 \pm 0.010$ & $0.049 \pm 0.001$ & $0.881 \pm 0.019$ \\
\hline 2 & $3.51 \pm 0.09$ & $44.8 \pm 1.2$ & $0.026 \pm 0.002$ & $0.336 \pm 0.026$ & $0.053 \pm 0.001$ & $0.674 \pm 0.010$ \\
\hline 3 & $3.34 \pm 0.08$ & $44.7 \pm 1.1$ & $0.024 \pm 0.001$ & $0.317 \pm 0.005$ & $0.053 \pm 0.001$ & $0.707 \pm 0.020$ \\
\hline 4 & $4.4 \pm 0.09$ & $63.9 \pm 1.3$ & $0.030 \pm 0.001$ & $0.423 \pm 0.009$ & $0.072 \pm 0.002$ & $1.033 \pm 0.025$ \\
\hline 5 & $3.12 \pm 0.08$ & $40.2 \pm 1.0$ & $0.023 \pm 0.001$ & $0.290 \pm 0.014$ & $0.059 \pm 0.002$ & $0.761 \pm 0.022$ \\
\hline 6 & $3.11 \pm 0.09$ & $40.9 \pm 1.0$ & $0.022 \pm 0.001$ & $0.286 \pm 0.014$ & $0.046 \pm 0.001$ & $0.615 \pm 0.011$ \\
\hline 7 & $3.62 \pm 0.08$ & $47.5 \pm 1.0$ & $0.026 \pm 0.001$ & $0.336 \pm 0.012$ & $0.043 \pm 0.001$ & $0.558 \pm 0.010$ \\
\hline 8 & $2.74 \pm 0.08$ & $37.7 \pm 1.1$ & $0.021 \pm 0.001$ & $0.294 \pm 0.12$ & $0.060 \pm 0.002$ & $0.598 \pm 0.032$ \\
\hline 9 & $5.35 \pm 0.08$ & $76.3 \pm 1.1$ & $0.034 \pm 0.001$ & $0.484 \pm 0.012$ & $0.044 \pm 0.002$ & $0.851 \pm 0.022$ \\
\hline 10 & $2.79 \pm 0.07$ & $35.9 \pm 0.9$ & $0.024 \pm 0.001$ & $0.307 \pm 0.010$ & $0.067 \pm 0.002$ & $0.570 \pm 0.021$ \\
\hline 11 & $3.45 \pm 0.06$ & $54.2 \pm 1.0$ & $0.032 \pm 0.001$ & $0.391 \pm 0.012$ & $0.058 \pm 0.001$ & $0.821 \pm 0.014$ \\
\hline 12 & $4.87 \pm 0.06$ & $69.5 \pm 0.8$ & $0.034 \pm 0.001$ & $0.485 \pm 0.014$ & $0.060 \pm 0.001$ & $0.830 \pm 0.016$ \\
\hline 13 & $5.01 \pm 0.07$ & $66.2 \pm 0.9$ & $0.031 \pm 0.001$ & $0.417 \pm 0.005$ & $0.052 \pm 0.001$ & $0.790 \pm 0.025$ \\
\hline 14 & $4.16 \pm 0.08$ & $54.9 \pm 1.1$ & $0.026 \pm 0.001$ & $0.414 \pm 0.012$ & $0.047 \pm 0.001$ & $0.689 \pm 0.008$ \\
\hline 15 & $3.45 \pm 0.08$ & $45.1 \pm 1.2$ & $0.026 \pm 0.001$ & $0.339 \pm 0.005$ & $0.048 \pm 0.001$ & $0.620 \pm 0.009$ \\
\hline 16 & $3.42 \pm 0.07$ & $44.6 \pm 0.9$ & $0.023 \pm 0.001$ & $0.333 \pm .010$ & $0.045 \pm 0.001$ & $0.630 \pm 0.001$ \\
\hline 17 & $2.86 \pm 0.07$ & $38.5 \pm 1.0$ & $0.026 \pm 0.001$ & $0.314 \pm 0.07$ & $0.045 \pm 0.002$ & $0.612 \pm 0.010$ \\
\hline 18 & $3.31 \pm 0.08$ & $40.9 \pm 1$ & $0.025 \pm 0.001$ & $0.318 \pm 0.016$ & $0.050 \pm 0.001$ & $0.558 \pm 0.020$ \\
\hline 19 & $3.53 \pm 0.04$ & $53.4 \pm 0.7$ & $0.025 \pm 0.001$ & $0.376 \pm 0.009$ & $0.043 \pm 0.001$ & $0.752 \pm 0.015$ \\
\hline 20 & $2.72 \pm 0.05$ & $37.1 \pm 0.6$ & $0.014 \pm 0.001$ & $0.188 \pm 0.004$ & $0.066 \pm 0.001$ & $0.583 \pm 0.001$ \\
\hline 21 & $6.05 \pm 0.11$ & $74.7 \pm 1.4$ & $0.040 \pm 0.001$ & $0.491 \pm 0.009$ & $0.082 \pm 0.001$ & $0.082 \pm 0.018$ \\
\hline 22 & $6.45 \pm 0.08$ & $75.6 \pm 0.9$ & $0.046 \pm 0.001$ & $0.539 \pm 0.015$ & $0.048 \pm 0.001$ & $0.812 \pm 0.014$ \\
\hline 23 & $3.68 \pm 0.05$ & $44.6 \pm 0.6$ & $0.029 \pm 0.001$ & $0.352 \pm 0.014$ & $0.082 \pm 0.001$ & $0.965 \pm 0.013$ \\
\hline 24 & $6.06 \pm 0.09$ & $68.2 \pm 0.09$ & $0.044 \pm 0.001$ & $0.491 \pm 0.013$ & $0.097 \pm 0.001$ & $0.582 \pm 0.013$ \\
\hline 25 & $10.07 \pm 0.15$ & $144.7 \pm 2.1$ & $0.060 \pm 0.001$ & $0.866 \pm 0.012$ & $0.042 \pm 0.003$ & $0.927 \pm 0.006$ \\
\hline 26 & $3.39 \pm 0.05$ & $42.2 \pm 0.7$ & $0.024 \pm 0.001$ & $0.300 \pm 0.009$ & $0.067 \pm 0.002$ & $1.398 \pm 0.037$ \\
\hline 27 & $4.25 \pm 0.06$ & $48.9 \pm 0.7$ & $0.032 \pm 0.001$ & $0.363 \pm 0.005$ & $0.062 \pm 0.001$ & $0.527 \pm 0.022$ \\
\hline 28 & $6.91 \pm 0.07$ & $75.5 \pm 0.8$ & $0.048 \pm 0.001$ & $0.523 \pm 0.009$ & $0.077 \pm 0.003$ & $0.765 \pm 0.009$ \\
\hline 29 & $4.94 \pm 0.07$ & $68.1 \pm 0.7$ & $0.036 \pm 0.001$ & $0.494 \pm 0.017$ & $0.025 \pm 0.001$ & $0.834 \pm 0.020$ \\
\hline 30 & $3.76 \pm 0.08$ & $55.5 \pm 1.2$ & $0.030 \pm 0.001$ & $0.440 \pm 0.007$ & $0.047 \pm 0.001$ & $0.541 \pm 0.010$ \\
\hline
\end{tabular}

FRAP determined using Pearson's correlation. The results were described using principal component analysis (PCA) and hierarchical cluster analysis (HCA) with Ward's method and Euclidean distances. Statistical and chemometric data analyses were performed using Statistica (Windows software package 8.0, Dell Inc., Tulsa, OK, USA).

\section{Results and discussion}

\subsection{Content of total phenolics}

The contents of total phenolics in the extracts obtained from grass pea ranged from 2.72 (LAT 494) to $10.07 \mathrm{mg} / \mathrm{g}$ extract (LAT 451) (Table 2). The results expressed per seed weight ranged from 35.9 (LAT 476) to $144.7 \mathrm{mg} / 100 \mathrm{~g}$ seeds (LAT 451) and these were lower than those for red bean, lentil, faba bean, and adzuki bean (Amarowicz and Pegg, 2008). Similar results were obtained for white bean by Orak et al. (2016) and for pea by Amarowicz and Troszyńska (2003). Fratianni et al (2014) reported similar content of total phenolics in two Italian varieties of grass pea (20.6 and $21.3 \mathrm{mg} / 100 \mathrm{~g})$. In the study of Wang et al. (1998), the content of total phenolics in Canadian grass pea ranged from 16.2 to $37.5 \mathrm{mg} / 100 \mathrm{~g}$. Seeds of Spanish, Italian, French, Polish, and German lines of Lthyrus sativus were characterized by the content of total phenolics that ranged from 20.3 to $70.3 \mathrm{mg} / 100 \mathrm{~g}$ (Rybiński et al., 2018). However, the higher 
Table 3. Content of phenolic acids in extracts and seeds from two grass pea cultivars

\begin{tabular}{|c|c|c|c|c|c|}
\hline \multirow{2}{*}{ Fraction } & \multirow{2}{*}{ Phenolic acids } & \multicolumn{2}{|c|}{ LAT 451} & \multicolumn{2}{|c|}{ LAT 494} \\
\hline & & (mg/g extract) & (mg/100 g seeds) & (mg/g extract) & (mg/100 g seeds) \\
\hline \multirow[t]{7}{*}{ Free } & $p$-Hydroxybenzoic & $0.003 \pm 0.000$ & $0.041 \pm 0.000$ & $0.003 \pm 0.000$ & $0.041 \pm 0.000$ \\
\hline & Protocatechuic & $<0.001$ & $<0.013$ & $<0.001$ & $<0.013$ \\
\hline & Gentisic & $0.002 \pm 0.000$ & 0.027 & $0.002 \pm 0.001$ & $0.027 \pm 0.014$ \\
\hline & $p$-Coumaric & $0.021 \pm 0.003$ & $0.284 \pm 0.041$ & $0.020 \pm 0.002$ & $0.270 \pm 0.027$ \\
\hline & Ferulic & $0.016 \pm 0.002$ & $0.216 \pm 0.027$ & $<0.001$ & $<0.013$ \\
\hline & Syringic & $0.300 \pm 0.032$ & $4.050 \pm 0.432$ & $0.231 \pm 0.021$ & $3.119 \pm 0.284$ \\
\hline & Sinapic & $0.015 \pm 0.001$ & $0.203 \pm 0.014$ & $0.006 \pm 0.001$ & $0.081 \pm 0.013$ \\
\hline \multirow{7}{*}{$\begin{array}{l}\text { Acids liberated } \\
\text { from esters }\end{array}$} & p-Hydroxybenzoic & $0.002 \pm 0.001$ & $0.027 \pm 0.014$ & $0.002 \pm 0.000$ & $0.027 \pm 0.014$ \\
\hline & Protocatechuic & $<0.001$ & $<0.013$ & $<0.001$ & $<0.013$ \\
\hline & Gentisic & $0.002 \pm 0.000$ & $0.027 \pm 0.000$ & $0.001 \pm 0.000$ & $0.014 \pm 0.000$ \\
\hline & p-Coumaric & $0.075 \pm 0.004$ & $1.013 \pm 0.054$ & $0.050 \pm 0.002$ & $0.675 \pm 0.027$ \\
\hline & Ferulic & $0.050 \pm 0.002$ & $0.675 \pm 0.027$ & $0.041 \pm 0.001$ & $0.554 \pm 0.014$ \\
\hline & Syringic & $0.130 \pm 0.010$ & $1.755 \pm 0.135$ & $0.328 \pm 0.036$ & $4.428 \pm 0.486$ \\
\hline & Sinapic & $0.424 \pm 0.042$ & $5.724 \pm 0.567$ & $0.214 \pm 0.035$ & $2.889 \pm 0.473$ \\
\hline \multirow{7}{*}{$\begin{array}{l}\text { Acids liberated } \\
\text { from glycosides }\end{array}$} & p-Hydroxybenzoic & $0.043 \pm 0.007$ & $0.581 \pm 0.095$ & $0.042 \pm 0.005$ & $0.567 \pm 0.066$ \\
\hline & Protocatechuic & $0.003 \pm 0.000$ & $0.041 \pm 0.000$ & $0.001 \pm 0.000$ & $0.014 \pm 0.000$ \\
\hline & Gentisic & $0.008 \pm 0.001$ & $0.108 \pm 0.014$ & $0.004 \pm 0.000$ & $0.054 \pm 0.000$ \\
\hline & $p$-Coumaric & $0.002 \pm 0.000$ & $0.027 \pm 0.000$ & $0.002 \pm 0.000$ & $0.028 \pm 0.000$ \\
\hline & Ferulic & $0.001 \pm 0.000$ & $0.014 \pm 0.000$ & $0.001 \pm 0.001$ & $0.014 \pm 0.000$ \\
\hline & Syringic & $0.037 \pm 0.004$ & $0.500 \pm 0.054$ & $0.014 \pm 0.001$ & $0.189 \pm 0.014$ \\
\hline & Sinapic & $0.007 \pm 0.001$ & $0.095 \pm 0.014$ & $0.009 \pm 0.001$ & $0.122 \pm 0.014$ \\
\hline
\end{tabular}

contents of total phenolic compounds in grass pea were reported by Carbonaro et al. (2015) and Wiszniewska and Piwowarczyk (2015).

\subsection{Antioxidant activity}

The results of the ABTS and FRAP assays are presented in Table 2. The results for the extracts were reported as Trolox equivalent antioxidant capacity (TEAC) values, ranging from 0.014 (LAT 494) to $0.060 \mathrm{mmol}$ Trolox/g extract (LAT 451) and by FRAP values that ranged from 0.025 (Canada C) to $0.082 \mathrm{mmol} \mathrm{Fe}{ }^{2+} / \mathrm{g}$ extract (LAT 440).

For seeds the results of TEAC and FRAP ranged from 0.188 (LAT 494) to $0.866 \mathrm{mmol} \mathrm{TE} / 100 \mathrm{~g}$ seeds (LAT 4076) and from 0.541 (UACH 2) to $1.398 \mathrm{mmol} \mathrm{Fe} \mathrm{e}^{2+} / 100 \mathrm{~g}$ seeds, respectively. Similar results of TEAC and FRAP were reported for white bean (Amarowicz and Pegg, 2008). Lower results were reported earlier for the European lines of grass pea: $0.158-0.372 \mathrm{mmol}$ Trolox/100 g seeds and $0.487-1.189 \mathrm{Fe}^{2+1} 100 \mathrm{~g}$ seeds, respectively (Rybiński et al., 2018).

The antioxidant potential of grass pea seeds has earlier been reported by several authors (Stanisavljević et al., 2013; Tamburino et al., 2012; Talukdar, 2012; Starzyńska-Janiszewska et al., 2011). In these determinations, FRAP, DPPH, and ABTS assays, as well as $\mathrm{H}_{2} \mathrm{O}_{2}$ scavenging, and $\beta$-carotene bleaching methods were employed.

\subsection{Content of individual phenolic compounds}

HPLC-MS was used for determination of phenolic compounds in grass pea. Results exhibited high (LAT 451) and low (LAT 494) antioxidant potential. Phenolic acids were the dominant phenolic compounds of grass pea (Table 3). The highest amounts found were syringic and sinapic acids. Ferulic, $p$-hydroxybenzoic, protocatechuic, and $p$-coumaric acids were present in much lower amounts. Only traces of gentisic acid were found. Phenolic acids were present in the form of free, esters, and glycosides. Syringic acid was determined mostly as free phenolic acid. Basic hydrolysis liberated the highest amount of sinapic acid from its esters. Relatively high amounts of $p$-hydroxybenzoic and syringic acids were liberated from glycosides after acidic hydrolysis. The contents of phenolic acids in the extract and seeds of LAT 451 were greater than those of LAT 494 (Table 3) Meanwhile the content of flavonoids in grass pea was very low. The presence of catechin, rutin, and isorhamnetin was confirmed using LC-MS (Table 4).

The presence of phenolic acids is typical for legume seeds. Ferulic acid was previously determined in broad bean, red bean, green lentil, and red lentil; $p$-coumaric acid in adzuki bean, broad bean, faba bean, red bean, green lentil, and red lentil; protocatechuic acid in adzuki bean and faba bean; $p$-hyrdoxybenzoic acid in faba bean and red bean; sinapic in red bean and red lentil (Amarowicz and Shahidi, 2017, 2018; Amarowicz et al., 2008, 2009, 2010, 2017). In terms of flavonoid content, grass pea is clearly different from 
Table 4. Content of flavonoids in extracts and seeds from two grass pea cultivars

\begin{tabular}{|c|c|c|c|c|}
\hline \multirow{2}{*}{ Flavonoids } & \multicolumn{2}{|c|}{ LAT 451} & \multicolumn{2}{|c|}{ LAT 494} \\
\hline & (mg/g extract) & (mg/100 g seeds) & (mg/g extract) & (mg/100 g seeds) \\
\hline Rutin & $0.003 \pm 0.000$ & $0.041 \pm 0.000$ & $0.003 \pm 0.000$ & $0.041 \pm 0.000$ \\
\hline Isorhamnetin & $0.001 \pm 0.000$ & $0.014 \pm 0.000$ & $0.001 \pm 0.000$ & $0.014 \pm 0.000$ \\
\hline Epicatechin & $0.012 \pm 0.001$ & $0.162 \pm 0.014$ & $0.013 \pm 0.001$ & $0.176 \pm 0.014$ \\
\hline
\end{tabular}
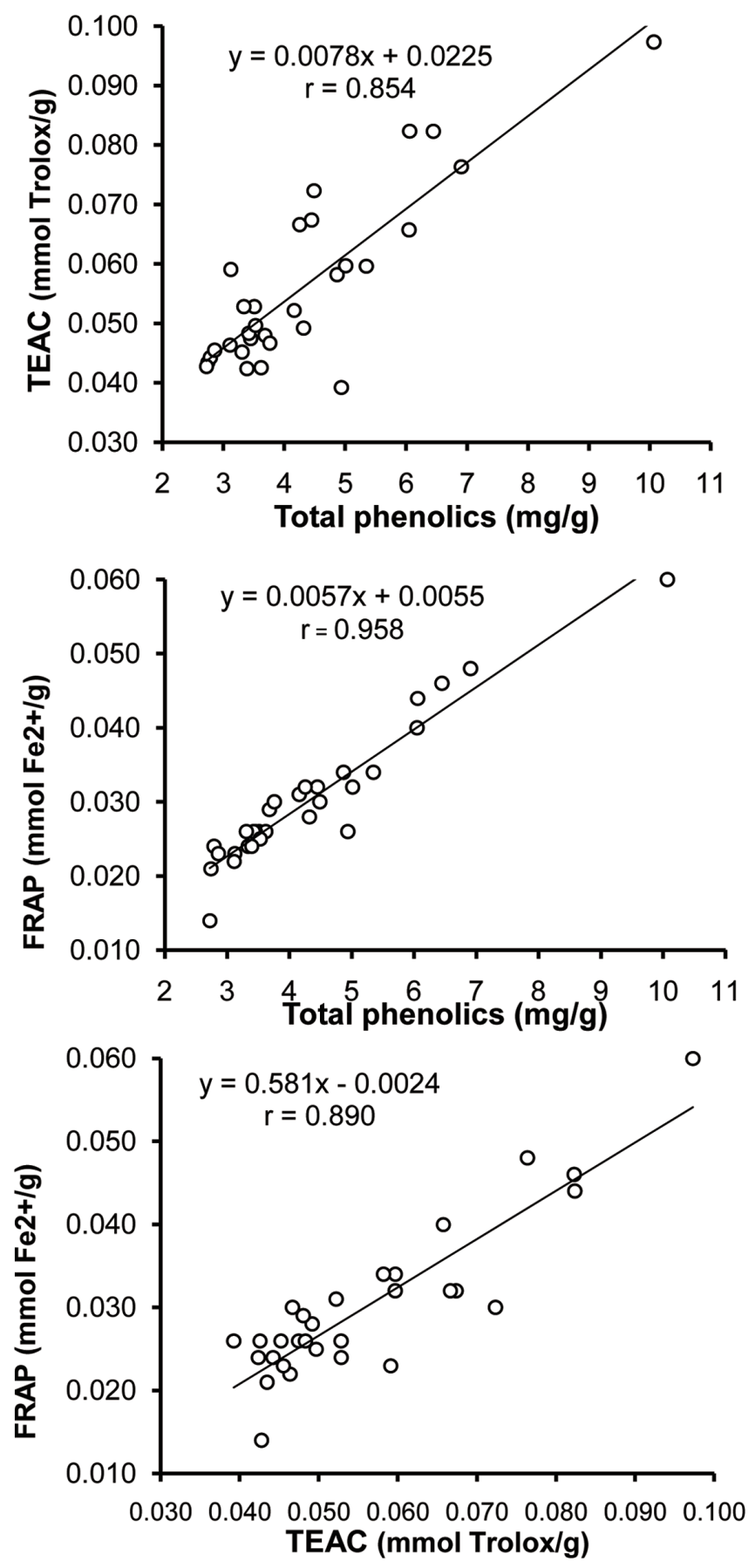

Figure 1. Correlation between the total phenolics content and the results of ABTS and FRAP assays and results of the two antioxidant assays. 


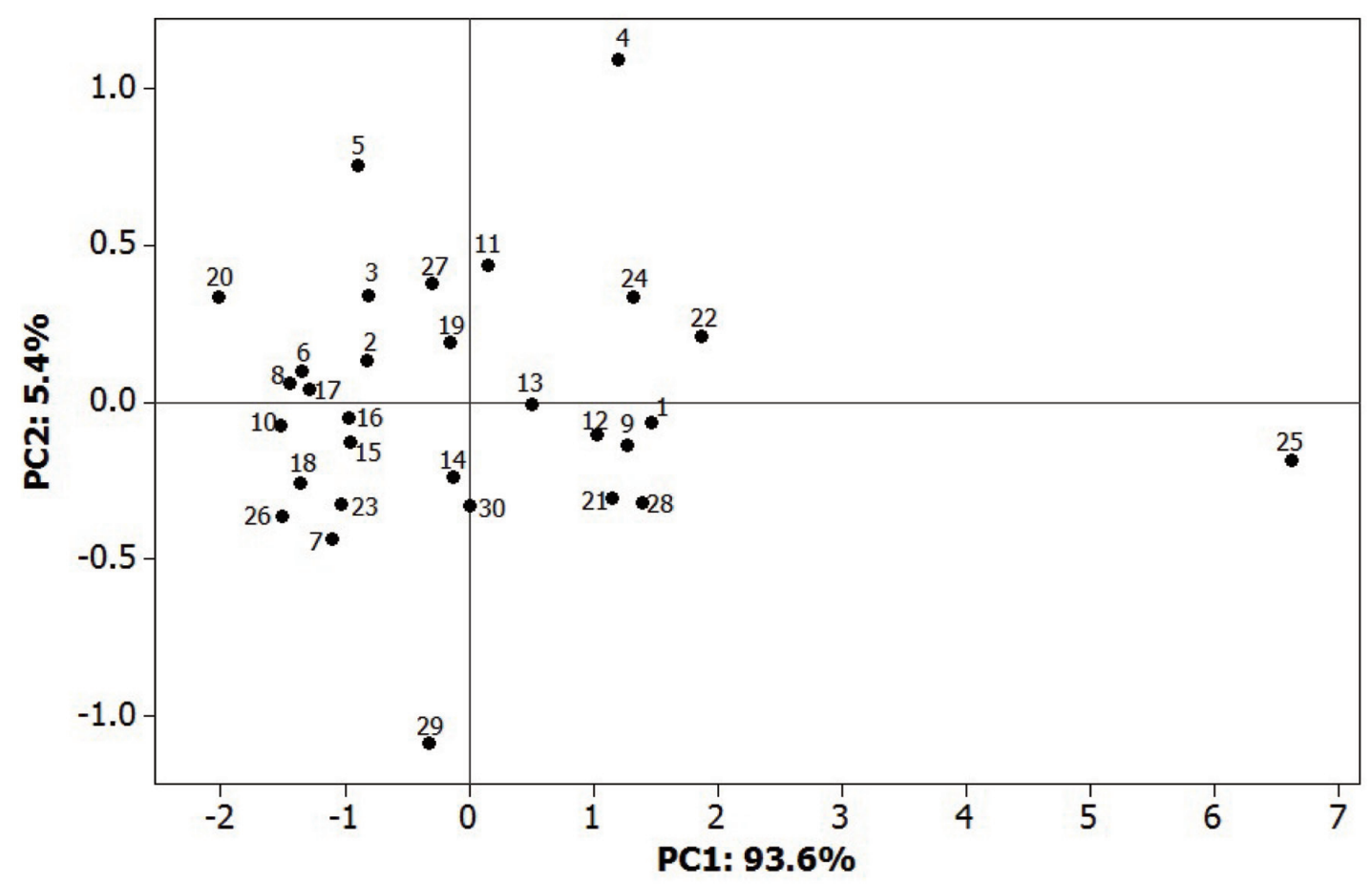

Figure 2. Results of the principal component analysis (PCA).

Tree Diagram for 30 Variables

Single Linkage

Euclidean distances

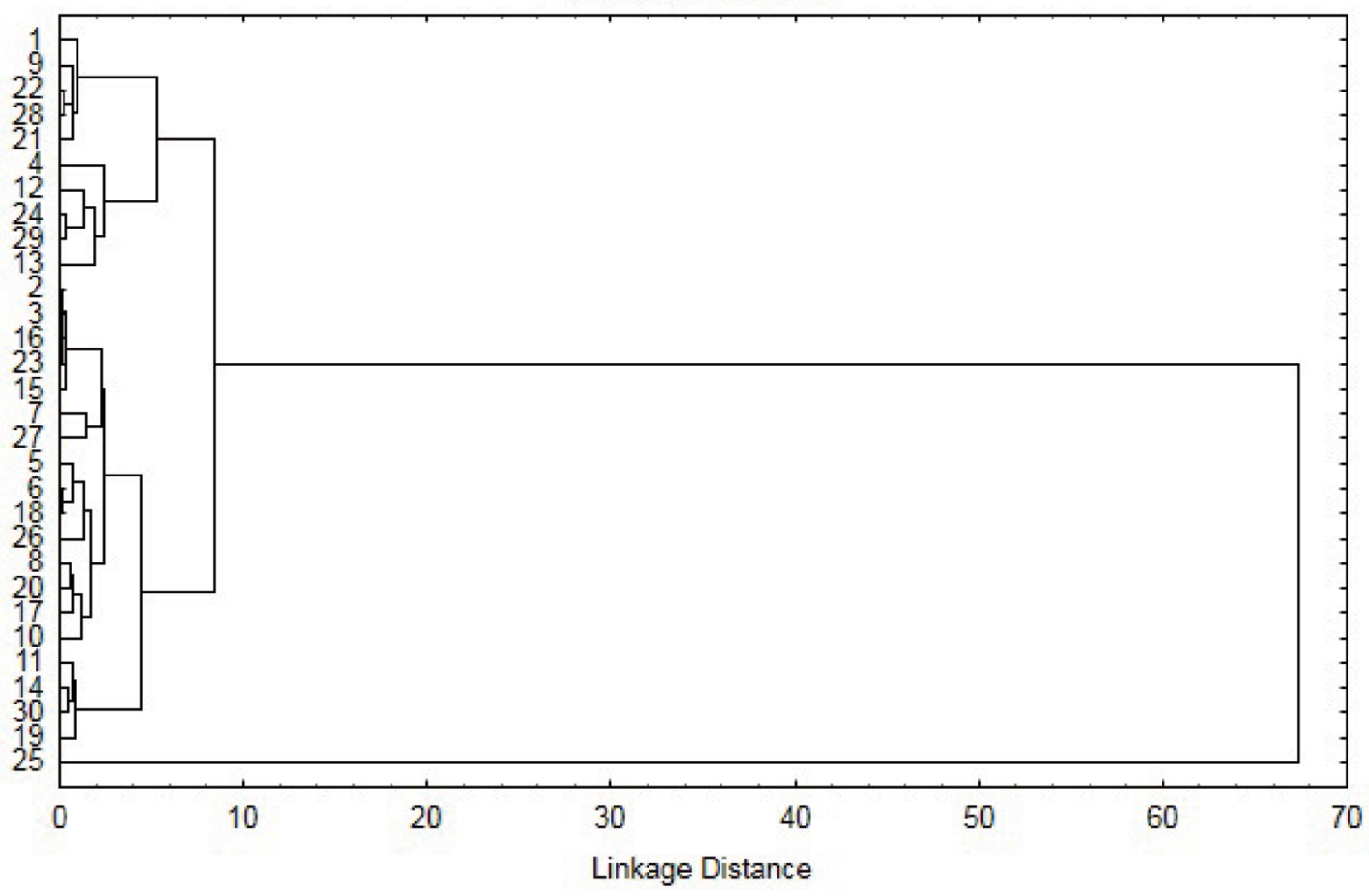

Figure 3. The hierarchical cluster analysis. 
other legumes which are generally rich in flavonoids (Amarowicz et al., 2009).

\subsection{Statistical analysis}

The antioxidant activity of the grass pea extracts was correlated with the content of total phenolics (Figure 1). The correlation coefficients between total phenolics and the results of ABTS and FRAP assays were 0.854 and 0.958 , respectively. This correlation was also observed in the results of both assays $(r=0.890)$. It is interesting that in the study of European lines of grass pea correlation between total phenolics and FRAP was much lower $(\mathrm{r}=0.781)$. Amarowicz et al. (2004) and Orak et al. $(2015,2016)$ previously reported previously similar correlation between the content of total phenolics in leguminous extracts.

In the principal component analysis (PCA) (Figure 2), the two first components accounted for $99.0 \%$ of the total variability between the Lathyrus sativus varieties. The greatest Mahalanobis distance was recorded for grass pea from Iran (25-LAT 451), Canada (29-Canada C), Hungary (20-LAT 494), and Slovakia (5-LAT 470 and 4-LAT 469). Taken under consideration grass pea seeds from Slovakia (samples 4-11 in Figure 2), discrimination of the sample geographical origin by PCA was rather difficult.

The hierarchical cluster analysis (Figure 3 ) confirmed that grass pea from Iran (25-LAT 451) was different from other samples. The presence of similar pairs of grass peas accessions from different countries (e.g., 24 from Bulgaria and 29 from Canada; 14 from Russia and 30 from Chile; 22 from India and 28 from Ethiopia) confirms the limitation of the hierarchical cluster analysis for the discrimination of the geographical origin of grass pea sample.

\section{Conclusion}

Grass pea is a potential legume crop with antioxidant potential similar to that of white bean and pea. Antioxidant activities of grass pea extracts (results of ABTS and FRAP assays) are strong correlated with the content of total phenolics. Application of the PCA and hierarchical cluster analysis for the discrimination of the grass pea sample geographical origin is limited.

\section{References}

Aletor, O., Onyemem, C.E., and Aletor, V.A. (2011). Nutrient constituents, functional attributes and in vitro protein digestibility of the seeds of the Lathyrus plant. WIT Trans. Ecol. Environ. 152: 145-155.

Alshikha, A., Camargo, C., and Shahidi, F. (2015). Phenolics of selected lentil cultivars: Antioxidant activities and inhibition of low-density lipoprotein and DNA damage. J. Funct. Foods 18: 1022-1038.

Amarowicz, R., and Pegg, R.B. (2008). Legumes as a source of natural antioxidants. Eur. J. Lipid Sci. Technol. 110: 865-878.

Amarowicz, R., and Shahidi, F. (2017). Antioxidant activity of broad bean seed extract and its phenolic composition. J. Funct. Foods 38: 656662

Amarowicz, R., and Shahidi, F. (2018). Antioxidant activity of faba bean extract and fractions thereof. J. Food Bioact. 2: 112-118.

Amarowicz, R., and Troszyńska, A. (2003). Antioxidant activity of extract of pea and its fractions of low molecular phenolics and tannins. Pol. J. Food Nutr. Sci. 12: 10-15.

Amarowicz, R., Estrella, I., Hernández, T., Dueñas, M., Troszyńska, A., Kosińska, A., and Pegg, R.B. (2009). Antioxidant activity of a red lentil extract and its fractions. Int. J. Mol. Sci. 10: 5513-5527.

Amarowicz, R., Estrella, I., Hernández, T., Robredo, S., Troszyńska, A.,
Kosińska, A., and Pegg, R.B. (2010). Free-radical scavenging capacity, antioxidant activity, and phenolic composition of green lentil (Lens culinaris). Food Chem. 12: 705-711.

Amarowicz, R., Estrella, I., Hernández, T., and Troszyńska, A. (2008). Antioxidant activity of extract of adzuki bean and its fractions. J. Food Lipids 15: 119-136.

Amarowicz, R., Karamać, M., Dueñas, M., and Pegg, R.B. (2017). Antioxidant activity and phenolic composition of a red bean (Phasoelus vulgaris) extract and its fractions. Nat. Prod. Comm. 12: 541-544.

Amarowicz, R., Troszyńska, A., Baryłko-Pikielna, N., and Shahidi, F. (2004). Polyphenolics extracts from legume seeds: Correlations between total antioxidant activity, total phenolics content, tannins content and astringency. J. Food Lipids 11: 278-286.

Benzie, I.E.F., and Strain, J.J. (1990). Ferric reducing/antioxidant power assay: Direct measure of total antioxidant activity of biological fluids and modified version for simultaneous measurement of total antioxidant power and ascorbic acid concentration. Methods Enzymol. 299: 15-27.

Bouchenak, M., and Lamri-Senhadji, M. (2013). Nutritional quality of legumes, and their role in cardiometabolic risk prevention: A review. J. Med. Foods 16: 185-198.

Carbonaro, M., Nardini, M., Maselli, P., and Nucara, A. (2015). Chemicophysical and nutritional properties of traditional legumes (lentil, Lens culinaris L., and grass pea, Lathyrus sativus L.) from organic agriculture: an explorative study. Org. Agric. 5: 179-292.

Chang, S.K., Alasalvar, C., and Shahidi, F. (2016). Review of dried fruits: Phytochemicals, antioxidant efficacies, and health benefits. J. Funct. Foods 21: 113-132.

Ennenking, D. (2011). The nutritive value of grasspea (Lathyrus sativus) and allied species, their toxicity to animals and the role of malnutrition in neurolathyrism. Food Chem. Toxicol. 49: 694-709.

Fratianni, F., Cardinale, F., Cozzolino, A., Granese, T., Albanese, D., Di Matteo, M., Zaccardelli, M., Coppola, R., and Nazzaro, F. (2014). Polyphenol composition and antioxidant activity of different grass pea (Lathyrus sativus), lentils (Lens culinaris), and chickpea (Cicer arietinum) ecotypes of the Campania region (Southern Italy). J. Funct. Foods 7: 551-557.

Getahun, H., Lambein, F., Vanhoorne, M., and Van der Stuyft, P. (2002). Pattern and associated factors of the neurolathyrism epidemic in Ethiopia. Trop. Med. Int. Health 7: 118-124.

Hanbury, C.D., White, C.L., Mullan, B.P., and Siddique, K.H.M. (2000). A review of the potential of Lathyrus sativus $L$. and $L$. cicera $L$. grain for use as animal feed. Anim. Feed Sci. Technol. 87: 1-27.

Hillocks, R.J., and Maruthi, M.N. (2012). Grass pea (Lathyrus sativus): Is there a case for further crop improvement? Euphytica 186: 647-654

Kumar, S., Bejiga, G., Ahmed, S., Nakkoul, H., and Sarker, A. (2011). Genetic improvement of grass pea for low neurotoxin ( $\beta$-ODAP) content. Food Chem. Toxicol. 49: 589-600.

Mikić, A., Mihailović, V., Ćupina, B., Ethurić, B., Krstić, D., Vasić, M., Vasiljević, S., Karagi, D., and Dorthević, V. (2011). Towards the reintroduction of grass pea (Lathyrus sativus) in the West Balkan countries: The case of Serbia and Srpska (Bosnia and Herzegovina). Food Chem. Toxicol. 49: 650-654.

Mullan, B.P., Pluske, J.R., Trezona, M., Harris, D.J., Allen, J.G., Siddique, K.H.M., Hanbury, C.D., van Barneveld, R.J., and Kim, J.C. (2009) Chemical composition and standardised ileal digestible amino acid contents of Lathyrus (Lathyrus cicera) as an ingredient in pig diets. Anim. Feed Sci. Technol. 150: 139-143.

Naczk, M., and Shahidi, F. (1989). The effect of methanol-ammonia-water treatment on the content of phenolic acids of canola. Food Chem. 31: 159-164.

Orak, H.H., Karamać, M., and Amarowicz, R. (2015). Antioxidant activity of phenolic compounds of red bean (Phaseolus vulgaris L.). Oxid. Commun. 38: 67-76.

Orak, H.-H., Karamać, M., Orak, A., and Amarowicz, R. (2016). Antioxidant potential and phenolic compounds of some widely consumed Turkish white bean (Phaseolus vulgaris L.) varieties. Pol. J. Food Nutr. Sci. 66: 253-260.

Pastor-Cavada, E., Jua, R., Pastor, J.E., Alai, M., and Vioque, J. (2010). Protein isolates from two Mediterranean legumes: Lathyrus clymenum and Lathyrus annuus. Chemical composition, functional properties 
and protein characterization. Food Chem. 122: 533-538.

Pastor-Cavada, E., Juan, R., Pastor, J.E., Alaiz, M., and Vioque, J. (2009). Fatty acid distribution in the feed flour of wild vicia species from Southern Spain. J Am. Oil. Chem. Soc. 86: 977-983.

Re, R., Pellegrini, N., Proteggente, A., Pannala, A., Yang, M., and Rice-Evans, C. (1999). Antioxidant activity applying an improved ABTS radical cation decolorization assay. Free Rad. Biol. Med. 26: 1231-1237.

Rybiński, W., Karamać, M., Sulewska, K., Börner, A., and Amarowicz, R. (2018). Antioxidant potential of grass pea seeds from European countries. Foods 7(9): 142.

Shahidi, F., Ramakrishnan, V.V., and Oh, W.Y. (2019a). Bioavailability and metabolism of food bioactives and their health effects: a review. J. Food Bioact. 8: 6-41.

Shahidi, F., and Ambigaipalan, P. (2015). Phenolics and polyphenolics in foods, beverages and spices: Antioxidant activity and health effectsA review. J. Funct. Foods 18: 820-897.

Shahidi, F., Vamadevan Varatharajan, V., Oh, W.Y., and Peng, H. (2019b). Phenolic compounds in agri-food by-products, their bioavailability and health effects. J. Food Bioact. 5: 57-119.

Srivastava, S., and Khokhar, S. (1996). Effect of processing on the reduction of $\beta$-ODAP ( $\beta$-N-oxalyl-1- $\alpha, \beta$-diaminopropionic acid) and antinutrients of khesari dhal. Lathyrus sativus. J. Sci. Food Agric. 71: 50-58.

Stanisavljević, N., Jovanović, Z., Čupić, T., Lukić, J., Miljuš Dukić, M.J., Radović, S., and Mikić, A. (2013). Extractability of antioxidants from legume seed flour after cooking and in vitro gastrointestinal digestion in comparison with methanolic extraction of the unprocessed flour.
Int. J. Food Sci. Technol. 48: 2096-2104.

Starzyńska-Janiszewska, A., and Stodolak, B. (2011). Effect of inoculated lactic acid fermentation on antinutritional and antiradical properties of grass pea (Lathyrus sativus "Krab") flour. Pol. J. Food Nutr. Sci. 61: 245-249.

Talukdar, D. (2012). Total flavonoids, phenolics, tannins and antioxidant activity in seeds of lentil and grass pea . Int. J. Phytomed. 4: 2096-2104.

Tamburino, R., Guida, V., Pacifico, S., Rocco, M., Zarelli, A., Parente, A., and Di Maro, A. (2012). Nutritional values and radical scavenging capacities of grass pea (Lathyrus sativus L.) seeds in Valle Agricola district, Italy. Austr. J. Crop Sci. 6: 149-156.

Valdez, J.C., Bradley, W., and Bolling, B.W. (2019). Anthocyanins and intestinal barrier function: a review. J. Food Bioact. 5: 18-30.

Wang, X., Warkentin, T.D., Briggs, C.J., Granese, T., Albanese, D., Di Matteo, M., Zaccardelli, M., Campbell, C.G., and Woods, S. (1998). Total phenolics and condensed tannins in field pea (Pisum sativum L.) and grass pea (Lathyrus sativus L.). Euphytica 101: 97-102.

Wiszniewska, A., and Piwowarczyk, B. (2015). Activity of selected components of antioxidant system in grass pea and yellow lupine protoplasts after enzymatic isolation. Biotechnologia 96: 285-292.

Yeo, J., and Shahidi, F. (2020). Identification and quantification of soluble and insoluble-bound phenolics in lentil hulls using HPLC-ESI-MS/MS and their antioxidant potential. Food Chem. 315: 126202.

Zhang, B., Peng, H., Deng, Z., and Rong Tsao, R. (2018). Phytochemicals of lentil (Lens culinaris) and their antioxidant and anti-inflammatory effects. J. Food Bioact. 1: 93-103. 